\title{
Finite Element Analysis for Optimal Heating Condition in Thermal Stress Cleaving of Brittle Materials using Laser Irradiation
}

\author{
Fumitaka Motomura ${ }^{1, a}$, Akihide Saimoto ${ }^{1, b}$ \\ ${ }^{1}$ Department of Mechanical Systems Engineering, Nagasaki University, 1-14 Bunkyo-machi, \\ Nagasaki 8528521, Japan \\ amotomura@nagasaki-u.ac.jp, bs-aki@nagasaki-u.ac.jp
}

Keywords: Finite Element Method, Thermal Stress Cleaving, Stress Intensity Factor.

\begin{abstract}
An optimal condition of thermal stress cleaving was investigated by assuming the element-by-element temperature rise situation using finite element method. The obtained thermal stress cleaving condition is found to be optimal for the symmetrical cleaving of a rectangular plate.
\end{abstract}

\section{Introduction}

A thermal stress cleaving (TSC) is a technique for processing a brittle material or introducing a shallow surface flaw by using a thermal stress. TSC has been employed preferably for the process of highly brittle materials. The most characteristic point of TSC is that this method is a non-contact production method which does not require any cutting tools or grinders. TSC also brings extremely strong surface which is free from micro-cracks only by providing an appropriate temperature distribution. When cleaving a glass plate using a laser irradiation, the crack tip propagates quasi statically following the moving heat center. Therefore the obtained crack path is almost identical to the locus of heat center. On the other hand, the crack propagation velocity varies considerably especially when the crack tip locates near the plate edges even when the laser heat source moves in a constant velocity. The crack propagation that follows a moving heat source can be treated quasi statically under the theory of thermo-elasticity and is analyzed quantitatively by finite element method [1-6]. In the present analysis a symmetrical cleaving problem of a rectangular plate is chosen as a numerical example. The analyzed region was discretized regularly by using a 4-noded isoparametric element of square shape and the stress intensity factor at a crack tip when only one element is assumed to be changed its temperature was analyzed as shown Figure 1. By superposing the obtained results, it is possible to predict an optimal heating shape which is advantageous from the view point of energy loss.

\section{Numerical Analysis}

In the present analysis, the plate length and the plate thickness were fixed at $100 \mathrm{~mm}$ and $1 \mathrm{~mm}$, respectively. The half plate width was changed 3-different values at 10, 25 and 50mm. The size of used finite elements were identical each other and the length of an element side was set at $1 \mathrm{~mm}$, $0.5 \mathrm{~mm}$ and $0.25 \mathrm{~mm}$. By changing the element size systematically, the extrapolated value of the stress intensity factor was obtained. The stress intensity factor was evaluated by virtual crack closure-integral method (VCCM). The material properties of soda-lime glass were used.

\section{Numerical Results}

Figure 2 shows a variation of stress intensity factor as a function of a central position of temperature raised element (central position). The temperature raised element is assumed to be adjacent to the symmetric axis. The area of temperature rise was assumed at $1 \mathrm{~mm}^{2}$. When the central position is close to the crack tip, stress intensity factor varied with the element size significantly. On the other 
hand, when the central position is far from crack tip, stress intensity factor is almost independent from the element size. This tendency holds irrespective to the crack tip position.

Figure 3 shows a contour map of the stress intensity factor in which the central position of temperature raised element that gives the identical stress intensity factor is connected to form contours. The used element size was $1 \mathrm{~mm}$ for this analysis and it was known from Fig. 2 that the stress intensity factor evaluated by this size of element gives under-estimated result. However, the sign of stress intensity factor is evaluated correctly. In Fig.3 the sign of stress intensity factor is interested from the practical view point. Within a region where positive stress intensity factor appeared, increasing a temperature of a region results an increase of the stress intensity factor. To the contrary within the region where negative stress intensity factor appeared, decreasing a temperature of a region results an increase of the stress intensity factor.

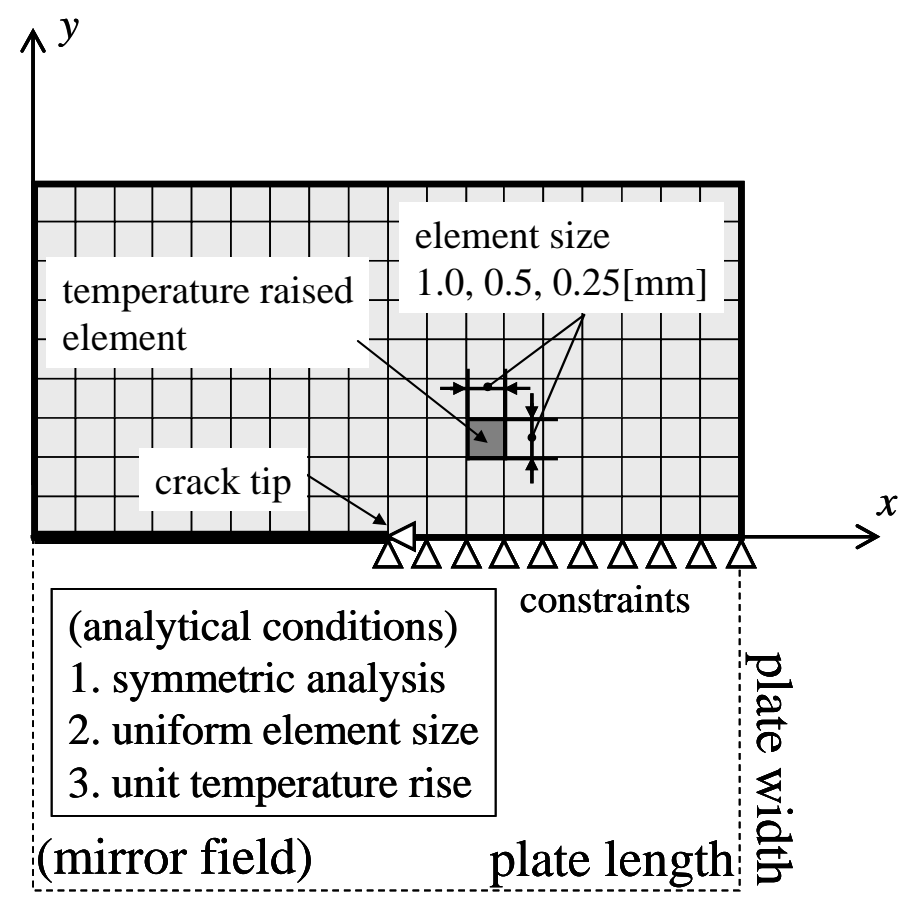

Fig.1 Analytical model

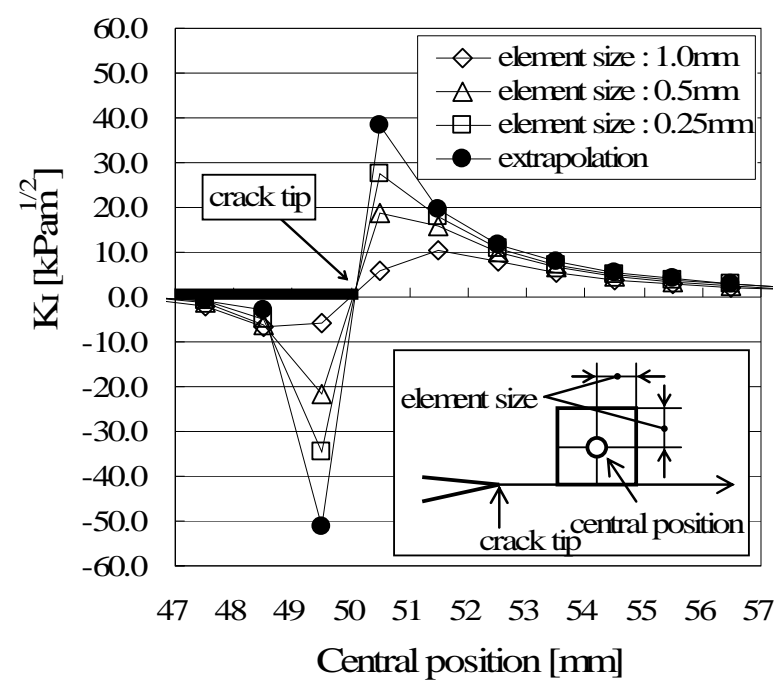

(a) Crack length 50mm

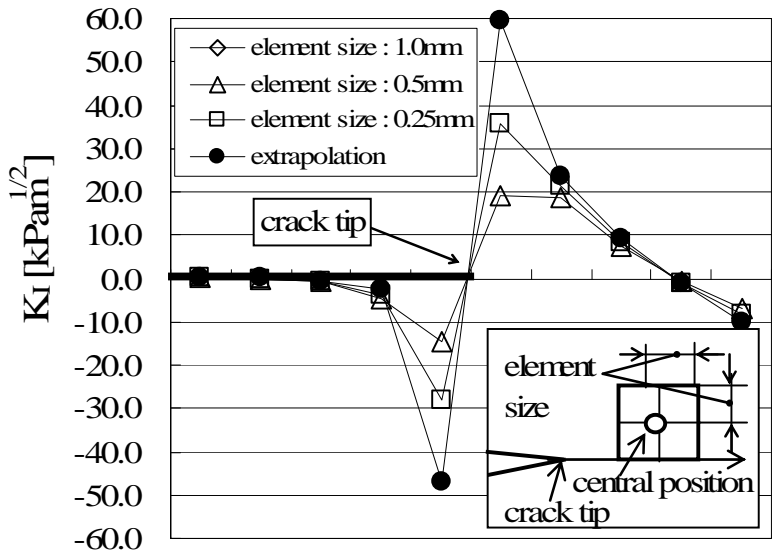

$\begin{array}{lllllllllll}90 & 91 & 92 & 93 & 94 & 95 & 96 & 97 & 98 & 99 & 100\end{array}$

Central position [mm]

(b) Crack length $95 \mathrm{~mm}$

Fig.2 Influence of element size on stress intensity factor 


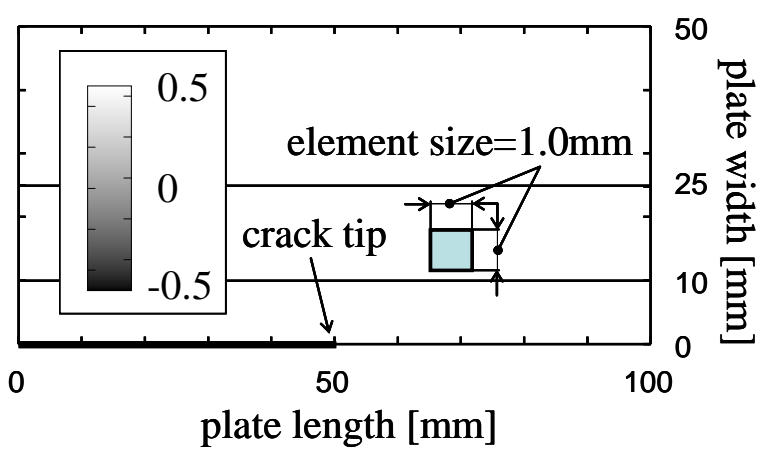

(a) Explanation of contour map

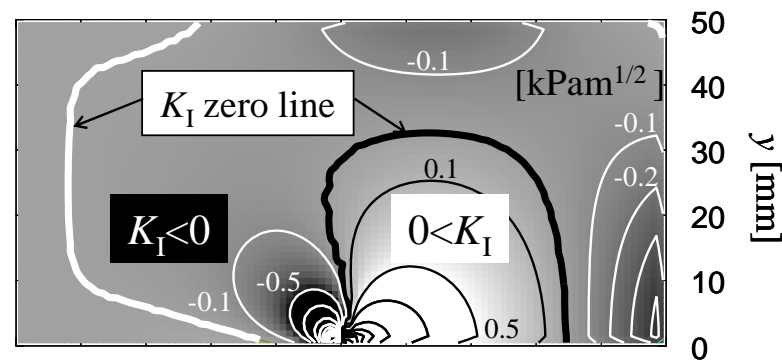

$\begin{array}{lllllllllll}0 & 10 & 20 & 30 & 40 & 50 & 60 & 70 & 80 & 90 & 100\end{array}$

(c) Result of middle crack size case

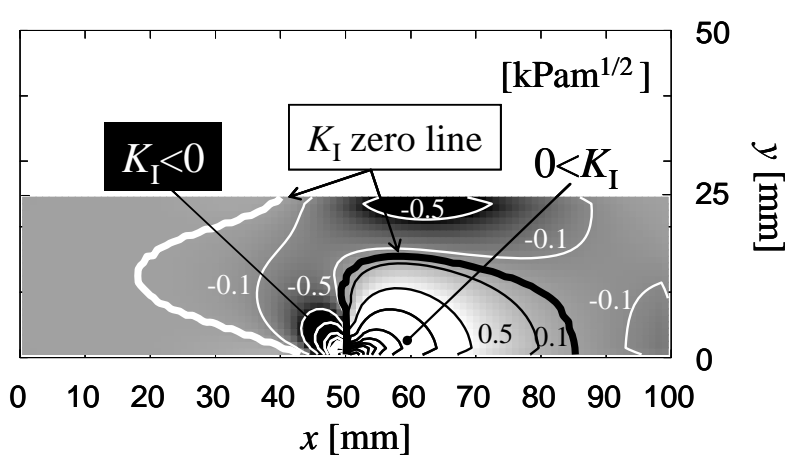

(e) Result of $25 \mathrm{~mm}$ width plate (middle crack size case)

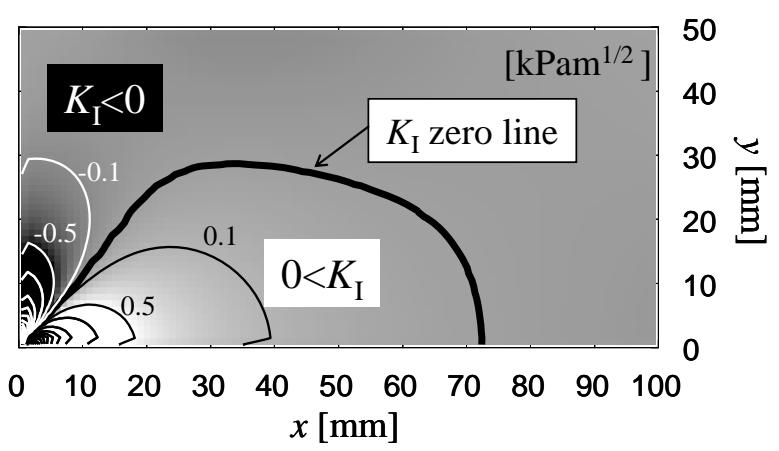

(b) Result of short crack case

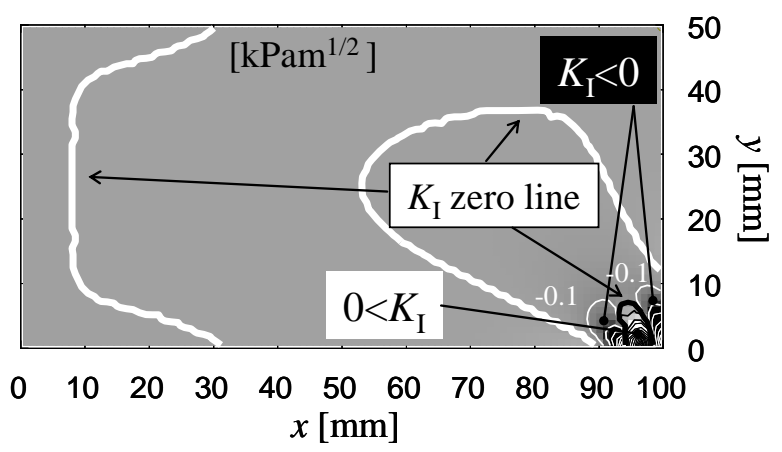

(d) Result of long crack case

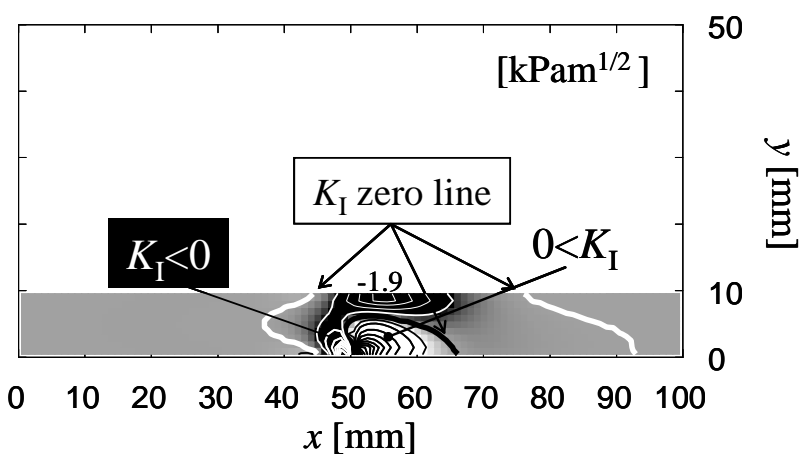

(f) Result of $10 \mathrm{~mm}$ width plate (middle crack size case)

Fig.3 The contour map of equal $K_{\mathrm{I}}$ value locations

The shape of the optimal heating area changes depending on the crack length. The positive mode I stress intensity factor is obtained when $60 \%$ of the plate width of the crack front region is heated when the crack tip is not extremely close to the plate edge. This tendency is not depend on the plate width. When the crack tip is very close to the plate edge, there exists a negative stress intensity factor zone near the plate edge. 


\section{Conclusion}

The optimal thermal stress cleaving condition was discussed for the case of symmetrical cleaving by using the finite element based thermo-elastic analysis. From the present analysis, the optimal cleaving condition for the rectangular plate was found.

\section{References}

[1] A. Saimoto, Y. Imai and F. Motomura, Transactions of the Japan Society of Mechanical Engineers, Vol.75, No.757 (2009), p.1202 (in Japanese)

[2] F. Motomura, Y. Imai and A. Saimoto, Journal of the Japan Society for Precision Engineers, Vol.75, No.11 (2009), p.1350 (in Japanese)

[3] F. Motomura, Y. Imai, A. Saimoto, Transactions of the Japan Society of Mechanical Engineers, Vol.75, No.755 (2009), p.925 (in Japanese)

[4] F. Motomura, Y. Imai, A. Saimoto, Journal of Solid Mechanics and Materials Engineering, Vol.3, No.3 (2009), p.529

[5] Y. Imai, A. Saimoto, F. Motomura, Transactions of the Japan Society of Mechanical Engineers, Vol.72, No.719 (2006), p.1003 (in Japanese)

[6] Y. Imai, A. Saimoto, F. Motomura, Transactions of the Japan Society of Mechanical Engineers, Vol.68, No.670 (2002), p.993 (in Japanese) 